\title{
Adherence of Multiple Serovars of Chlamydia trachomatis to a Common Receptor on HeLa and McCoy Cells Is Mediated by Thermolabile Protein(s)
}

\author{
By EVANGELIA VRETOU, $†$ PRABHAT C. GOSWAMI \\ AND SUBIR K. BOSE* \\ Department of Microbiology, St Louis University School of Medicine, St Louis, MO 63104, USA
}

(Received 12 June 1989; revised 17 August 1989; accepted 12 September 1989)

\begin{abstract}
Several aspects of the adherence of purified elementary bodies (EB) of Chlamydia trachomatis to HeLa and to McCoy cells were examined using different techniques, including an ELISA. Serovar-specific, biotinylated monoclonal antibodies were used to detect cell-bound chlamydiae. In addition, purified chlamydiae were biotinylated and their adherence properties were studied. The assays were done at $4{ }^{\circ} \mathrm{C}$ to exclude the energy-dependent internalization of the cell-bound EB and host-cell membrane recycling that occur at $37^{\circ} \mathrm{C}$. Saturation kinetics were routinely observed at $4{ }^{\circ} \mathrm{C}$, and the rate of adherence remained linear for approximately $60 \mathrm{~min}$. Lineweaver-Burk analysis of the kinetics data showed that adherence of any one serovar was competitively inhibited by other serovars of $C$. trachomatis. This competition for the same receptor on the two alternative hosts, $\mathrm{HeLa}$ and $\mathrm{McCoy}$, was also seen when the adherence assays were done at $37^{\circ} \mathrm{C}$ in the presence of sodium azide, an energy poison that inhibits endocytosis of cell-bound chlamydiae. Chlamydiae exposed to $56^{\circ} \mathrm{C}$ for $5 \mathrm{~min}$, or treated with low doses of trypsin, failed to exhibit competitive inhibition, having suffered considerable loss of the ability to adhere to host-cells. These data suggest that heat- and trypsin-labile chlamydial moieties participate in the adherence reaction, and that oculo-genital serovars of $C$. trachomatis, including that of lymphogranuloma venereum, attach to the same receptor on the host-cell membrane.
\end{abstract}

\section{INTRODUCTION}

Chlamydia trachomatis is an obligate intracellular bacterial pathogen that must attach to the membrane of a susceptible eukaryotic cell in order to initiate its replication cycle. Little is known about the nature of the chlamydial surface-exposed ligand(s) that recognize specific receptors on the host-cell membrane. Heat-lability of attachment, as first noted by Kuo \& Grayston (1976) and by Byrne \& Moulder (1978), suggests the participation of a proteinaceous component in the infectious entity, the so-called elementary body (EB). In our studies (Bose \& Smith, 1984; Bose \& Goswami, 1986a,b), the rate of chlamydial adherence was assayed at 4 or $5{ }^{\circ} \mathrm{C}$ in order to exclude the post-adherence internalization of the cell-bound EB and the recycling of the host-receptor that normally occur at higher temperatures. While Kuo \& Grayston (1976) noted that association at room-temperature of both LGV L2 and the B serovar of $C$. trachomatis with HeLa cells was drastically reduced when radioactively labelled EB were exposed to $56^{\circ} \mathrm{C}$ for $30 \mathrm{~min}$, Lee (1981) was unable to detect heat-lability of association of $C$. trachomatis serovar A with McCoy cells at $37^{\circ} \mathrm{C}$. We observed that only during incubation of the $\mathrm{EB} /$ host-cell reactants at $5{ }^{\circ} \mathrm{C}$ could heat-lability of adherence both of LGV and non-LGV serovars be discerned (Bose \& Goswami, 1986a). Detection of the response to lectin wheat-germ agglutinin and to haptenic sugars also requires incubation at $5^{\circ} \mathrm{C}$ (Bose \& Goswami, 1986a).

† Permanent address: Institut Pasteur Hellenique, Athens 115 21, Greece.

Abbreviations: EB, elementary bodies; HSC, HEPES/sucrose/cation buffer. 
Reduced adherence to glycosylation-defective mutants of $\mathrm{CHO}$ cells is detectable only when the assays are done at $4{ }^{\circ} \mathrm{C}$ (Bose \& Goswami, 1986b).

By enzyme-linked immunoassay (ELISA) utilizing serovar-specific monoclonal antibodies, biotinylated EB, and radiolabelled, purified $E B$, we investigated several aspects of the adherence properties of $\mathrm{LGV} \mathrm{Ll}$ and two non-LGV serovars of $C$. trachomatis to the two alternative hosts, HeLa and McCoy cells. Under appropriate conditions of assay, saturation kinetics were readily observed with the serovars examined.

Some of the data reported here were first presented by Vretou et al. $(1988 a, b)$.

\section{METHODS}

Organisms. C. trachomatis serovars B, E and LGV440 (L1) were grown in HeLa and in McCoy cells (Bose \& Goswami, 1986a). Chlamydia-infected cells were disrupted by sonication with glass beads (Vibra-Cell sonicator; $30 \%$ output, $6 \mathrm{~mm}$ microtip). Cellular debris was removed by centrifugation at $200 \mathrm{~g}$ for $10 \mathrm{~min}$, and the supernatant was filtered through a $600 \mathrm{~nm}$ pore-size polycarbonate membrane (Nuclepore) to remove the chlamydial reticulate bodies (Bose \& Paul, 1982). The EB were purified using a Percoll gradient procedure (Newhall et al., 1982), and single-use aliquots were stored at $-80^{\circ} \mathrm{C}$ in HEPES/sucrose/cation buffer (HSC; $10 \mathrm{~mm}$-HEPES, $\mathrm{pH} 7 \cdot 3,1 \mathrm{~mm}-\mathrm{MgCl}_{2}, 1.5 \mathrm{~mm}-\mathrm{CaCl}_{2}, 90 \mathrm{~mm}-\mathrm{NaCl}, 0.2 \mathrm{M}$-sucrose).

In order to determine the extent to which any host-derived protein co-purified with the final EB preparation, a mixing experiment was done using chlamydia-infected cells and uninfected host-cells labelled with a tritiated amino acids mixture. Less than $0.02 \%$ of the label appeared in the purified EB (Table 1). Electron microscope examination of the EB preparations showed that unless filtration of the low-speed supernatant through a $600 \mathrm{~nm}$ pore-size polycarbonate membrane (Bose \& Paul, 1982) was included, the samples contained about $20 \%$ chlamydial reticulate bodies as had been noted by Newhall et al. (1982).

Biotinylation of the EB. Percoll-purified EB suspension was adjusted to a protein concentration of $1 \mathrm{mg} \mathrm{ml}^{-1}$ and centrifuged in an Eppendorf microcentrifuge for $15 \mathrm{~min}$ at $4^{\circ} \mathrm{C}$. After carefully removing the supernatant, the EB were resuspended at the same concentration in $0.1 \mathrm{M}$-sodium bicarbonate containing $0.145 \mathrm{M}-\mathrm{NaCl}$ and $0.2 \mathrm{M}$ sucrose (pH 8.0). Sulfo-NHS-biotin (Pierce Chemical Co.) was dissolved in water at $1 \mathrm{mg} \mathrm{ml}^{-1}$, and $5 \mu 1$ was added per $100 \mu \mathrm{l}$ of the EB suspension. After gentle mixing, the suspension was kept at $0^{\circ} \mathrm{C}$ for $2 \mathrm{~h}$. Biotinylation was stopped by adding 2 vols of serum-free minimum essential medium, and after $15 \mathrm{~min}$ the mixture was applied to a Sephadex G-25 Quicksep column (Isolab) pre-equilibrated with 0.5\% (w/v) BSA in PBS (Bose \& Goswami, $1986 a$ ). Fractions ( 100 to $150 \mu \mathrm{l}$ ) were collected and the presence of EB in the fractions was detected using a dot assay with a serovar-specific monoclonal antibody. In several experiments, purified radioactively labelled EB were co-chromatographed and served as a marker. Fractions 7,8 and 9 containing the biotinylated $\mathrm{EB}$ were pooled. The EB were concentrated by centrifugation, resuspended in HSC buffer and stored at $-80^{\circ} \mathrm{C}$.

Assay for chlamydial adherence to cell cultures. A, Biotinylated monoclonal antibody-based assessment. This technique was developed by Ridderhof \& Barnes (1988), who used KB-8, the E- and L1-specific monoclonal antibody to assay chlamydial adherence to HeLa cultures in 96-well dishes. Briefly, the anti-B (DH-8) and anti-E (KB-8) immunoglobulins, kindly provided to us as ascites fluid by Dr Robert C. Barnes of the Centers for Disease Control, Atlanta, GA, USA, were purified using a Beckman recombinant protein A-agarose column, and after dialysis against $0.1 \mathrm{M}$-sodium bicarbonate, $\mathrm{pH} 8.0$, biotinylation was effected with biotin succinimide. Following dialysis against PBS containing $0.02 \%$ sodium azide, the IgG was stabilized with $1 \mathrm{mg} \mathrm{BSA} \mathrm{ml}{ }^{-1}$.

HeLa or McCoy cells were plated in 96-well cell culture dishes at $5 \times 10^{4}$ cells in $200 \mu \mathrm{l}$ of growth medium per well and incubated at $37^{\circ} \mathrm{C}$. The next day the medium was carefully aspirated and the wells were filled with icecold growth medium. After $30 \mathrm{~min}$ at $0^{\circ} \mathrm{C}$, the monolayers were washed once with ice-cold PBS, and the assay was initiated in triplicate wells by addition of $25 \mu \mathrm{l}$ per well of appropriately diluted, purified EB suspension in HSC buffer. Incubation was for 45 to $60 \mathrm{~min}$ at $4{ }^{\circ} \mathrm{C}$ with continuous rocking on a Bellco rocker set at maximum speed. The adherence reaction was stopped by adding $200 \mu$ lice-cold PBS to each well, and the monolayers were washed rapidly with ice-cold PBS at least three times. The cells were fixed with methanol. For the ELISA, methanol was removed and the fixed cells were washed three times with PBS, blocked for $1 \mathrm{~h}$ with $3 \%(\mathrm{w} / \mathrm{v}) \mathrm{BSA}$ in PBS at $37^{\circ} \mathrm{C}$, and then incubated with biotinylated monoclonal antibody for $1 \mathrm{~h}$ at $37^{\circ} \mathrm{C}$. After washing five times with PBS containing $0.01 \%$ Tween 20 , the biotinylated anti-chlamydial $\operatorname{IgG}$ bound to the EB attached to the host cells was detected quantitatively with streptavidin-conjugated $\beta$-galactosidase, using $o$-nitrophenyl galactopyranoside as the chromogen.

$B$, Direct assay with biotinylated $E B$. When biotinylated EB were used, the cell-bound EB were detected with streptavidin-conjugated $\beta$-galactosidase. Identical results were obtained using either assay procedure.

$C$, Assay with radioactively labelled EB. Adherence assays with EB labelled during intracellular replication with a mixture of ${ }^{35}$ S $]$ methionine and ${ }^{[35}$ S $]$ cysteine (Trans S; ICN Radiochemicals, Irvine, CA) were done in 24-well or 96-well multidishes as described earlier (Bose \& Paul, 1982; Bose et al., 1983; Bose \& Goswami, 1986a). 
Table 1. Host-protein contribution to the EB of C. trachomatis serovar B purified by the modified Percoll procedure

A tritiated amino acid mixture was used to label the proteins of uninfected HeLa $229 \mathrm{Gl}$ cells. The labelled cells were mixed with unlabelled HeLa cells infected with serovar B, and the EB were purified essentially according to Newhall et al. (1982) (see Methods). The low-speed supernatant was filtered through a $600 \mathrm{~nm}$ pore-size polycarbonate membrane filter. Samples $(10 \mu \mathrm{l})$ were removed at each step, and hot-TCA-precipitable radioactivity was determined. A parallel extract of labelled, uninfected $\mathrm{HeLa}$ cells was simultaneously processed; the radioactivity appearing in the final pellet was $0.02 \%$ of the starting material, the same as in the purified EB (data not shown).

\begin{tabular}{|c|c|c|c|}
\hline Fraction & $\begin{array}{l}\text { Vol. } \\
\text { (ml) }\end{array}$ & $\begin{array}{c}10^{-5} \times \text { Total } \\
\text { radioactivity } \\
\text { (c.p.m.) }\end{array}$ & $(\%)$ \\
\hline Sonicate & $12 \cdot 0$ & 287 & $(100)$ \\
\hline Low-speed supernatant & 11.5 & 187 & $(65)$ \\
\hline $30000 \mathrm{~g}$ pellet & $2 \cdot 0$ & $19 \cdot 8$ & (7) \\
\hline Percoll-layer pellet & $1 \cdot 4$ & 0.518 & $(0.18)$ \\
\hline $\begin{array}{l}\text { Pellet, through } 30 \% \\
\text { sucrose cushion }\end{array}$ & 0.5 & 0.07 & $(0.02)$ \\
\hline
\end{tabular}

\section{RESULTS}

In our previous studies on the adherence characteristics of $C$. trachomatis to monolayer cultures of HeLa, McCoy and $\mathrm{CHO}$ cells and the glycosylation-defective mutant cell lines of CHO (Bose \& Paul, 1982; Bose et al., 1983; Bose \& Goswami, 1986a, b) we utilized metabolically radioactively labelled, highly purified preparations of chlamydial EB. Whenever possible, the data obtained with radioactive EB were confirmed by infectivity determinations. However, the experiments with highly radioactive preparations suffered from the fact that radioactive decay occurred in the ${ }^{32} \mathrm{P}$ - or ${ }^{35} \mathrm{~S}$-labelled material, resulting in the loss of infectivity, and the possible introduction of artifacts in these assays. We therefore sought to develop assays that did not require radioactive material, and could be used to screen monoclonal-antibodyproducing hybridomas that affected chlamydial adherence. Use of either biotinylated monoclonal anti-chlamydial IgG or biotinylated EB enabled us to do the adherence assays in 96well dishes, and to bypass the need for radioactively labelled chlamydiae. Comparison of the data obtained with the three different techniques convinced us that while detection of the cellbound EB did not approach the sensitivity obtained with ${ }^{32} \mathrm{P}$-labelled material (Bose \& Smith, 1984), all three methods for the adherence assay provided equivalent data. Of the several serovar-B-specific monoclonal antibodies tested, only one, DH-8, was found to be capable of detecting cell-surface-bound EB. In the experiments with the serovar E, the monoclonal antibody utilized was KB-8. The epitopes recognized by these monoclonal antibodies were not heat-labile as measured by dot assay or ELISA (data not shown).

\section{Adherence of C. trachomatis serovars B and E to HeLa and McCoy cells is mediated via heat-labile and heat-stable ligands}

Adherence assays were done at $4{ }^{\circ} \mathrm{C}$ to distinguish the initial attachment of the EB to the hostcell membrane from the subsequent temperature-dependent endocytosis step. The rate of adherence of serovar E to McCoy cell monolayers remained linear for approximately $75 \mathrm{~min}$, declining thereafter (Fig. 1), as reported previously with serovar K (Bose \& Goswami, 1986a). Similar kinetics of adherence were obtained with serovar B and HeLa or McCoy cells (data not shown). Therefore, all adherence kinetic-studies reported here were done at $4{ }^{\circ} \mathrm{C}$, with the incubation period not exceeding $60 \mathrm{~min}$. Using ELISA-based detection of the cell-associated $\mathrm{EB}$, exposure of the $\mathrm{EB}$ suspension to $56^{\circ} \mathrm{C}$ for $10 \mathrm{~min}$ resulted in a 30 to $50 \%$ reduction in adherence rate (Fig. 1). Assays done at $37^{\circ} \mathrm{C}$ indicated no reduction in the adherence rate of heated EB (data not shown), similar to the situation noted with serovars A (Lee, 1981), and K (Bose \& Goswami, 1986a). Further incubation of the EB at $56{ }^{\circ} \mathrm{C}$ did not result in additional decrease in the chlamydial adherence-rate (data not shown), suggesting the participation of additional heat-stable chlamydial adhesin(s) in this reaction. 


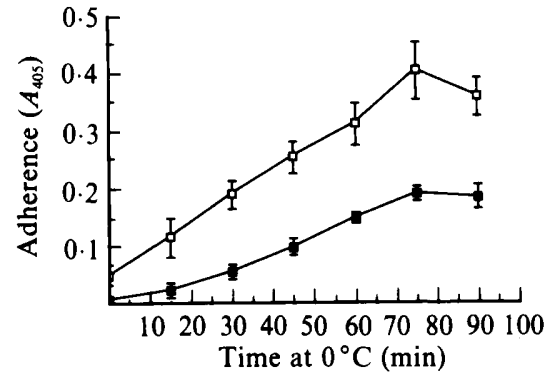

Fig. 1

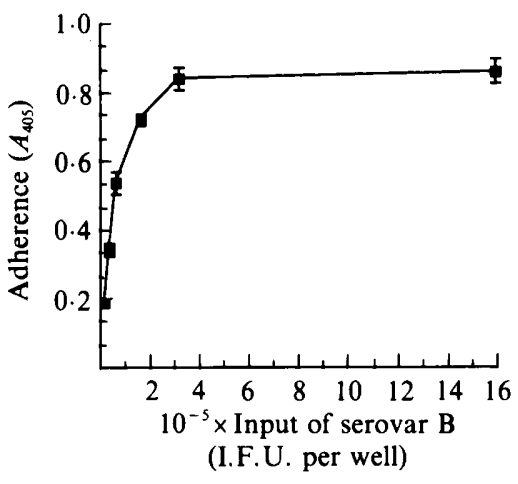

Fig. 2

Fig. 1. Kinetics of adherence of purified EB of serovar E to McCoy cell monolayers, before ( $\square$ ) and after (घ) exposure to $56^{\circ} \mathrm{C}$ for $10 \mathrm{~min}$. The assay was done at $0^{\circ} \mathrm{C}$ in a 96 -well cell culture dish. Cell-bound $C$. trachomatis was detected by biotinylated monoclonal antibody KB-8. The experiment was repeated five times. The bars represent SD values from triplicate samples.

Fig. 2. Adherence of biotinylated EB of C. trachomatis serovar B to HeLa cell monolayers at $4{ }^{\circ} \mathrm{C}$ for 60 min as a function of chlamydial dose. Similar data were obtained in four experiments with different preparations of chlamydiae. The bars represent SD values from triplicate samples.

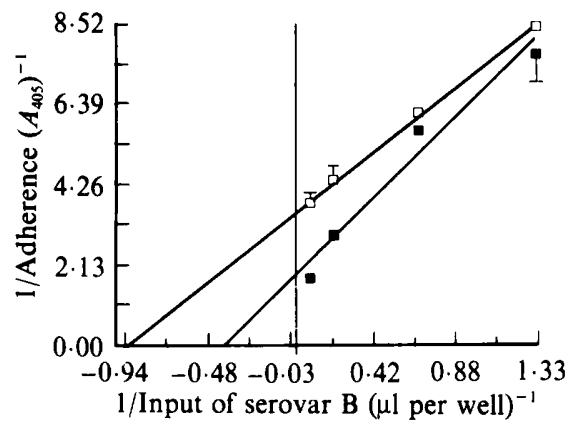

Fig. 3. Double-reciprocal plot of the adherence rates of $C$. trachomatis serovar B to McCoy cell monolayers, before ( $\square$ ) and after $(\square)$ heating at a temperature of $56^{\circ} \mathrm{C}$ for $10 \mathrm{~min}$, as a function of chlamydial dose. After incubation at $4{ }^{\circ} \mathrm{C}$ for $60 \mathrm{~min}$, cell-bound EB were detected with biotinylated monoclonal antibody DH-8. The Figure was generated with the Analytical Graphics program for an Apple micro-computer, using linear regression to draw the lines. The experiment was repeated three times.

\section{Saturation of chlamydial receptors on HeLa and McCoy cells}

With increasing input of purified biotinylated EB of serovar B to HeLa cells, a MichaelisMenten type of adherence kinetics with rectangular hyperbolae could be reproducibly obtained (Fig. 2). Saturation of adherence with increasing chlamydial dose was obtained with LGV L1 and serovars $B$ and $E$ as well using the monoclonal-antibody-based detection with both host-cell types (data not shown).

A double-reciprocal plot of the data with serovar B showed that the EB, after exposure to $56{ }^{\circ} \mathrm{C}$ for $10 \mathrm{~min}$, exhibited a $50 \%$ reduction in the value for $V$ and a doubling of the apparent $K_{\mathrm{m}}$ (Fig. 3), suggesting that heat-denatured EB may bind to alternate receptors on McCoy cells via modified ligands.

\section{Adherence of one serovar is inhibited by other serovars in a competitive manner}

We tested the effect of addition of heterologous serovars of $C$. trachomatis EB on the adherence of serovar B. Purified EB of serovars Ll and E were added along with varying doses of the test serovar B to monolayers of McCoy cells. Cell-bound serovar B chlamydiae were 


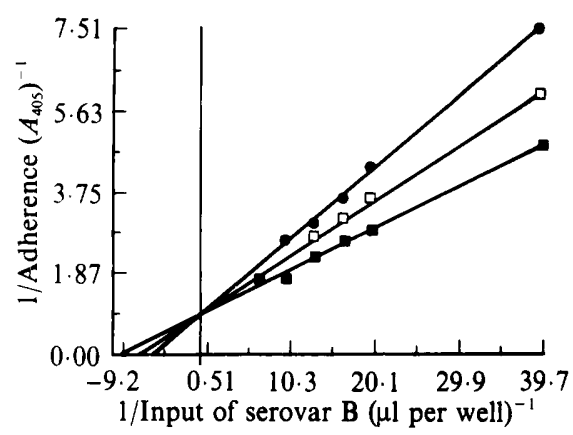

Fig. 4. Double-reciprocal plot of adherence rates of EB of C. trachomatis serovar B to McCoy cell

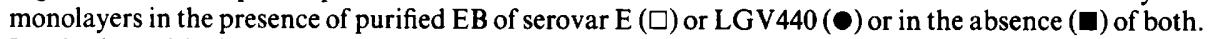
Incubation with the McCoy cell monolayers in 96-well dishes was for $60 \mathrm{~min}$ at $4{ }^{\circ} \mathrm{C}$. The ordinate represents the reciprocal of the adherence rates, as assayed in triplicate; the abscissa is the reciprocal of the input of serovar B. Cell-bound serovar B EB were detected using biotinylated monclonal antibody DH-8. Essentially similar results were obtained in three different experiments. The Figure was computer-generated as in Fig. 3.

detected using the biotinylated monoclonal antibody DH-8. Fig. 4 is a double-reciprocal plot of the data from such an experiment, showing that both the LGV serovar L440 (L1) and the nonLGV serovar E competitively inhibited adherence of the trachoma serovar B to host-cells, with all three curves approaching the same values for $V$. The competitive nature of the inhibition suggests that the different serovars, including the LGV, bind to the same receptor on the hostcell membrane.

Adherence assays were also done at $37^{\circ} \mathrm{C}$ in the presence of the energy poison sodium azide to prevent internalization of the cell-bound EB. Under these conditions, competitive inhibition of the adherence of $\left[{ }^{35}\right.$ S $]$ methionine $/\left[{ }^{35} S\right]$ cysteine-labelled $E B$ of serovar $E$ to HeLa cells by serovars B and $\mathrm{L} 1$ was found (Fig. 5). This indicates that the reactions studied at $4{ }^{\circ} \mathrm{C}$ were not qualitatively different from those at $37^{\circ} \mathrm{C}$ provided the energy poison was used, and that at the higher temperture the serovars of $C$. trachomatis attached to the same receptor on both HeLa and McCoy cells. In the absence of azide, no inhibition by the other serovars was seen. In separate experiments, using radiolabelled $\mathrm{Ll}$, competitive inhibition of association by serovar $\mathrm{E}$ has been observed at $37^{\circ} \mathrm{C}$ in azide-poisoned HeLa and McCoy cells (data not shown).

Using very low inputs of the test serovar in the presence of the inhibitory serovars, evidence for co-operativity of adherence (Bose \& Smith, 1984) has been repeatedly obtained. Under these conditions, the heterologous serovars produced a 2- to 3-fold stimulation of adherence of the biotinylated test serovar (data not shown).

\section{Heat-labile, trypsin-sensitive chlamydial adhesin}

When suspensions of EB of serovars E or LGV440 were exposed to $56^{\circ} \mathrm{C}$ for $5 \mathrm{~min}$, no inhibition of adherence of serovar B to the host-cell monolayer was seen (Table 2), indicating that the heat-denatured chlamydiae were unable to exhibit interfering activity, even though the heated EB exhibited some residual adherence ability (Figs 1 and 3). In addition, exposure of the purified EB of serovar E or LGV440 to $1 \mu \mathrm{g}$ trypsin per $10 \mu \mathrm{g}$ EB protein for $2 \mathrm{~h}$ at $37^{\circ} \mathrm{C}$ resulted in a significant decrease in inhibitory activity of the two serovars on adherence of serovar $\mathrm{B}$ to McCoy cells. These results indicated that competitive inhibition by the heterologous serovars was mediated by thermolabile protein(s) on the chlamydiae. Trypsin- and heat-treatment of the purified EB resulted in a significant decrease in their ability to exhibit co-operativity-related stimulation of adherence at the low input, discussed in the preceding paragraph (data not shown). It has been shown that infectivity, i.e. inclusion-forming activity of serovars $B$ and $C$ was inhibited by addition of heat-inactivated $\mathrm{B}$ or $\mathrm{C}$, while that of $\mathrm{L} 2$ was relatively unaffected (Kuo et al., 1973). In that study, heated L2 had no effect on the infectivity of serovars B, C or L2. 


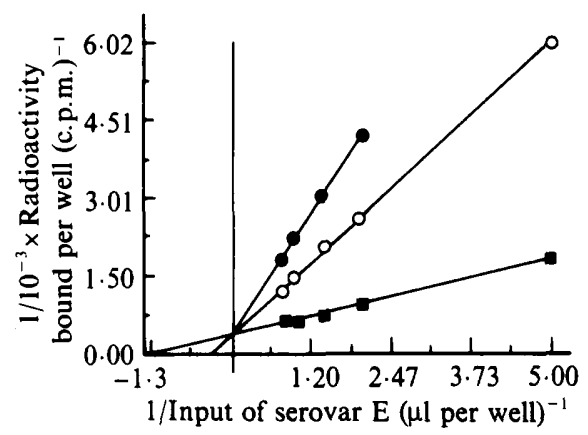

Fig. 5. Double-reciprocal plot of adherence rates of $\left[{ }^{35} S\right]$ methionine $/\left[{ }^{35} S\right]$ cysteine labelled serovar $\mathrm{E}$ to HeLa cells in the presence of purified EB of serovar B (O) or LI (O), or in the absence ( $\square)$ of both. Incubation was for $60 \mathrm{~min}$ at $37^{\circ} \mathrm{C}$ in the presence of $5 \mathrm{~mm}$-sodium azide. The ordinate represents the reciprocal of the adherence rates, expressed as cell-bound EB per well, assayed in triplicate; the abscissa is the reciprocal of the input of labelled EB of serovar E. The Figure was computer-generated as in Figs 3 and 4 . The experiment was repeated three times.

Table 2. Loss of inhibition of adherence of C. trachomatis serovar B to McCoy cells by serovars $E$ and LGV440 following heat and trypsin treatment

Cell-adherent serovar B was detected using monoclonal antibody DH-8, following incubation at $4{ }^{\circ} \mathrm{C}$ for $45 \mathrm{~min}$, as described in Methods. The $A_{405}$ of the control was 0.678 . Purified EB of serovar E and LGV440 were treated with $1 \mu \mathrm{g}$ typsin per $10 \mu \mathrm{g}$ chlamydial protein for $2 \mathrm{~h}$ at $37^{\circ} \mathrm{C}$ prior to their addition to monolayer cultures of McCoy cells. This experiment was repeated four times.

$\begin{array}{lc}\text { Addition } & \begin{array}{c}\text { Adherence rate of } \\ \text { serovar B } \\ (\% \text { control })\end{array} \\ \text { None } & 100 \\ \text { Serovar E } & 55 \\ 56^{\circ} \mathrm{C}, 5 \mathrm{~min} & 99 \\ 15 \text { min } & 102 \\ \text { Trypsin-treated } & 81 \\ \text { LGV440 } & 46 \\ 56^{\circ} \mathrm{C}, 5 \text { min } & 100 \\ 15 \text { min } & 103 \\ \text { Trypsin-treated } & 77\end{array}$

The adherence ability of trypsin-treated EB of the LGV serovar L1 was examined. The epitope recognized by monoclonal antibody KB-8 was found to be trypsin-sensitive. Therefore, the experiment was done with radioactively labelled EB. In three separate experiments adherence of the $\left.{ }^{35} \mathrm{~S}\right]$ methionine $/\left[{ }^{35} \mathrm{~S}\right]$ cysteine-labelled $\mathrm{Ll} C$. trachomatis exposed to $1 \mu \mathrm{g}$ trypsin per $10 \mu \mathrm{g} \mathrm{EB}$ protein for $60 \mathrm{~min}$ at $37^{\circ} \mathrm{C}$ was inhibited by more than $95 \%$ when the assays were done at $4{ }^{\circ} \mathrm{C}$ (data not shown). No inhibition was detected when the adherence assays were done at $37^{\circ} \mathrm{C}$, confirming results with the L2 serovar (Bose \& Paul, 1982; Hackstadt \& Caldwell, 1985; Su et al., 1988). A double-reciprocal plot of the data obtained at $4{ }^{\circ} \mathrm{C}$ with multiple inputs of untreated and trypsin-treated $\mathrm{L} 1$ revealed that, in addition to the decrease in $V$, the apparent $K_{\mathrm{m}}$ of adherence by treated EB was 100-fold higher (data not shown).

\section{DISCUSSION}

The results of our previous studies (Bose \& Goswami, 1986a, b) on the adherence characteristics of $C$. trachomatis showed the necessity of distinguishing the initial attachment of the chlamydial EB from the subsequent ingestion process, which occurs at temperatures above 
$22{ }^{\circ} \mathrm{C}$. A number of significant properties of chlamydial adherence to cell monolayers can be observed only when assays are done at $4-5^{\circ} \mathrm{C}$. For example, inhibition of adherence of HeLaadapted $C$. trachomatis (Bose \& Goswami, 1986a), and altered adherence in glycosylationdefective mutant $\mathrm{CHO}$ cell lines (Bose \& Goswami, 1986 b) can be detected at $5^{\circ} \mathrm{C}$ but not at $37^{\circ} \mathrm{C}$. In contrast to the impaired association of EB of C. psittaci, C. trachomatis serovar L1 (Byrne, 1976; Byrne \& Moulder, 1978), and C. trachomatis serovars L2 and B (Kuo \& Grayston, 1976) exposed to $56^{\circ} \mathrm{C}$ for $30 \mathrm{~min}$, no inhibition can be detected with similarly treated serovar $\mathrm{A}$ (Lee, 1981). Exposure of purified EB of serovar $\mathrm{K}$ to $60^{\circ} \mathrm{C}$ for $5 \mathrm{~min}$ causes a diminution of the rate of adherence, but only when the assays are done at $5^{\circ} \mathrm{C}$ (Bose \& Goswami, 1986a), or at $37^{\circ} \mathrm{C}$ in the presence of sodium azide (unpublished observations). In addition, the adherence rate of heated EB of serovar A (Lee, 1981) and of K (Bose \& Goswami, 1986a) is significantly greater than that of unheated $\mathrm{EB}$ at $37^{\circ} \mathrm{C}$. Kinetic analyses of data on attachment of unheated and heated EB of serovar B show that both $V$ and the apparent $K_{\mathrm{m}}$ of the EB/cell attachmentreaction are altered (Fig. 3), suggesting that the chlamydial ligands may bind to alternate receptors on the host-cell membrane, presumably due to conformational changes due to the heat treatment.

Lectin-stimulated adherence of HeLa-adapted $\mathrm{L} 1$ to $\mathrm{HeLa}$ cells can be detected at $37^{\circ} \mathrm{C}$ only when the monolayers are pretreated with sodium azide, and we concluded that under these conditions the cell-bound lectin remained externally disposed, providing additional binding sites for the EB (Bose \& Goswami, 1986a). Soderlund \& Kihlstrom (1983) noted that attachment of McCoy-adapted L1 to McCoy cells is inhibited by wheat-germ agglutinin at $4{ }^{\circ} \mathrm{C}$ but not at $37^{\circ} \mathrm{C}$. Lack of interference of the association of the L2 serovar and E to McCoy cells by $\mathrm{N}$ acetylglucosamine and its oligomers has been recorded at $35^{\circ} \mathrm{C}$ (Allan \& Pearce, 1987). Therefore, considerable attention must be paid to assay conditions, especially temperature, when only the initial adherence process without the concomitant ingestion of the cell-associated $\mathrm{EB}$ and membrane recycling is examined. It may be that specificity of attachment is discernible only in the absence of internalization of the bound ligand, i.e. the EB. It should be noted that EB that are allowed to attach to host-cells at 4 or $5^{\circ} \mathrm{C}$ remain fully functional in that upon subsequent incubation at 35 or $37^{\circ} \mathrm{C}$, unimpaired inclusion formation is detected. Data summarized in Fig. 5 show that when energy-dependent processes, e.g. membrane recycling, receptor regeneration and internalization of the cell-bound EB are prevented in the presence of sodium azide, competitive inhibition of the adherence of one serovar by other serovars can be readily seen at $37^{\circ} \mathrm{C}$.

Using serovars LGV L1, B and E, saturable adherence is reproducibly obtained (Figs 2 and 3). The inability to achieve saturable adherence of $C$. psittaci to L cells (Byrne, 1978) or of $C$. trachomatis LGV L1 to McCoy cells (Soderlund \& Kihlstrom, 1983) can be attributed to the temperature at which assays were done, i.e. $37^{\circ} \mathrm{C}$ rather than $4{ }^{\circ} \mathrm{C}$. At $37^{\circ} \mathrm{C}$, adherence as well as ingestion of chlamydiae occur, in addition to host-membrane recycling and rapid regeneration of receptors as noted with C. trachomatis serovar Ll (Bryne \& Moulder, 1978).

Serovars E and LGV L1 inhibited adherence of serovar B, and adherence of L1 was inhibited by serovar $E$, provided the energy-dependent ingestion of cell-bound chlamydiae was prevented. Graphical analysis of the kinetic data by Lineweaver-Burk method (Figs 4 and 5) indicates that the inhibition is competitive type. This suggests that the three different serovars, including LGV, attach to the same receptor on the host-cell membrane. The LGV serovars, in contrast to the non-LGV ones, are far more efficient in terms of infectivity and adherence. The greater efficiency of infection by the LGV serovars does not imply that they bind to a different receptor, rather it may reflect greater avidity. The data summarized in Table 2 show that on exposing an EB suspension to $56^{\circ} \mathrm{C}$ for $5 \mathrm{~min}$, the inhibitory activity of the $\mathrm{Ll}$ and E serovars was greatly diminished. These results are not in accord with those reported by Kuo et al. (1973) who found heat-inactivated chlamydiae to be potent inhibitors of infectivity. Presumably, postinternalization events, such as phagolysosomal fusion and activation of lysosomal degradative enzymes were affected by the denatured EB. The heated EB that do attach to the host-cells (Figs 1 and 3), therefore, appear to be unable to interfere with adherence of the test serovar. The heatlability of interference would suggest that competitive inhibition of adherence by undenatured 
EB is mediated via thermolabile ligands, though adherence may additionally involve thermostable adhesin(s). Parasite-induced phagocytosis of $C$. psittaci and $C$. trachomatis by nonprofessional phagocytes such as L and HeLa cells was deduced by Byrne \& Moulder (1978), based on the thermolability of the chlamydial ligands responsible for the ingestion of EB. Alternatively, the denatured EB may bind nonspecifically to different receptors on the host-cell membrane, probably via heat-modified ligands in view of the different apparent $K_{\mathrm{m}}$ of adherence (Fig. 3).

The $18 \mathrm{kDa}$ eukaryotic-cell-binding polypeptide that has been isolated from serovar L2 of $C$. trachomatis (Hackstadt, 1986; Wenman \& Meuser, 1986) does not appear to be the one that our studies would implicate in adherence or in interference of adherence of EB. The $18 \mathrm{kDa}$ polypeptide adheres to isolated membrane preparations from $\mathrm{HeLa}$ cells after chlamydial samples are boiled in lysis buffer and resolved in SDS-polyacrylamide gels (Hackstadt, 1986; Wenman \& Meuser, 1986). It may be that chlamydial adherence to the host-cell membrane is mediated by heat-labile as well as heat- and SDS-resistant ligands, possibly to alternative receptors.

Monoclonal antibodies that interfere with adherence of EB to host-cells have not been reported, although several do inhibit intracellular replication (Caldwell \& Perry, 1982; Lucero \& Kuo, 1985; Peeling et al., 1984). The location of the chlamydial adhesin is such that it is accessible to the host-cell receptor via glycosylated residues on the cell membrane. However, immunoglobulins directed against the serovar-, species- or genus-specific epitopes are unable to interact with the ligand responsible for the attachment step, as was proposed by Zhang et al. (1987). It is significant that the treatment of EB of serovar B, but not L2, with trypsin resulted in the proteolysis of the externally disposed VDII domain in the outer-membrane protein complex, and resulted in a partial inhibition of association of trypsinized EB to HeLa cells at $37^{\circ} \mathrm{C} \mathrm{(Su} \mathrm{et}$ al., 1988). Our studies show that mild trypsinization of both LGV and non-LGV serovars results in almost complete inhibition of adherence to HeLa cells assayed at $4{ }^{\circ} \mathrm{C}$. Such EB are also incapable of competitively inhibiting the adherence of untreated EB (Table 2). Trypsinization of the $\mathrm{L} 2$ serovar is innocuous both with respect to association with $\mathrm{HeLa}$ cells at $37^{\circ} \mathrm{C}$ and infectivity (Bose \& Paul, 1982; Hackstadt \& Caldwell, 1985; Su et al., 1988). Adherence exclusive of ingestion is greatly diminished due to trypsin treatment of purified EB, regardless of the serovar, and such chlamydiae are incapable of interfering with the adherence of heterologous serovars.

The importance of adhesin topology is also suggested by the lack of competition with EB heated at $56^{\circ} \mathrm{C}$ for $5 \mathrm{~min}$, a treatment presumably sufficient to alter the conformation of the adhesin in the outer-membrane complex. We suggest, therefore, that the chlamydial heat-labile adhesin may not be totally exposed and that its function is dependent on the native conformation of the chlamydial outer-membrane complex within which these moieties lie.

The data presented here indicate that chlamydial adherence may be a multi-factorial process involving heat-labile as well as heat-stable adhesins. A study of this process alone, without the subsequent energy-dependent internalization of cell-bound chlamydiae, reveals that only heatlabile proteinaceous adhesins of multiple serovars of $C$. trachomatis exhibit similar kinetic parameters and compete for the same receptors on the two alternative hosts. Heated or trypsintreated chlamydiae show altered adherence characteristics, presumably due to modifications of the adhesins. With the occurrence of energy-dependent internalization, some of these parameters may become masked.

This work was supported by grants from the Edna McConnell Clark Foundation, the NATO Scientific Affairs Division, and the National Institutes of Health (AI-19575). We thank Professor L. J. Tolmach for valuable help in the preparation of the manuscript and Tana $M$. Wensel for her secretarial expertise.

\section{REFERENCES}

Allan, I. \& Pearce, J. H. (1987). Association of Chlamydia trachomatis with mammalian and cultured insect cells lacking putative chlamydial receptors. Microbial Pathogenesis 2, 63-70.
Bose, S. K. \& Goswami, P. C. (1986a). Host modification of the adherence properties of Chlamydia trachomatis. Journal of General Microbiology 132 , 1631-1639. 
Bose, S. K. \& Goswami, P. C. (1986b). Chlamydial adherence to glycosylation-defective mutants of Chinese hamster cell lines. In Chlamydial Infections, pp. 31-34. Edited by D. Oriel, G. Ridgway, J. Schachter, D. Taylor-Robinson \& M. Ward. Cambridge: Cambridge University Press.

Bose, S. K. \& PaUl, R. G. (1982). Purification of Chlamydia trachomatis lymphogranuloma venereum elementary bodies and their interaction with $\mathrm{HeLa}$ cells. Journal of General Microbiology 128, 13711379.

Bose, S. K. \& SMITH, G. B. (1984). Positive cooperativity in the adherence between elementary bodies of Chlamydia trachomatis strain UW-31 and HeLa cells. FEMS Microbiology Letters 23, 55-58.

Bose, S. K., Smith, G. B. \& Paul, R. G. (1983). Influence of lectins, hexoses, and neuraminidase on the association of purified elementary bodies of Chlamydia trachomatis UW-31 with HeLa cells. Infection and Immunity 40, 1060-1067.

BYRNE, G. I. (1978). Kinetics of phagocytosis of Chlamydia psittaci to mouse fibroblasts ( $\mathrm{L}$ cells): separation of the attachment and ingestion stages. Infection and Immunity 19, 607-612.

Byrne, G. I. \& Moulder, J. W. (1978). Parasitespecified phagocytosis of Chlamydia psittaci and Chlamydia trachomatis by $\mathrm{L}$ and HeLa cells. Infection and Immunity 19, 598-606.

Caldwell, H. D. \& Perry, L. J. (1982). Neutralization of Chlamydia trachomatis infectivity with antibodies to the major outer membrane protein. Infection and Immunity 38, 745-754.

HACKSTADT, T. (1986). Identification and properties of chlamydial polypeptides that bind eucaryotic cell surface components. Journal of Bacteriology 165, 13 20.

HackstadT, T. \& Caldwell, H. D. (1985). Effect of proteolytic cleavage of surface-exposed proteins on infectivity of Chlamydia trachomatis. Infection and Immunity 48, 546-551.

Kuo, C.-C., WanG, S.-P. \& Grayston, J. T. (1973). Effects of polycations, polyanions and neuraminidase on the infectivity of trachoma-inclusion conjunctivitis and lymphogranuloma venerum organisms in $\mathrm{HeLa}$ cells: sialic acid residues as possible receptors for trachoma-inclusion conjunctivitis. Infection and Immunity 8, 74-79.

Kuo, C.-C. \& Grayston, J. T. (1976). Interaction of Chlamydia trachomatis organisms and HeLa cells. Infection and Immunity 13, 1103-1109.

LEE, C. K. (1981). Interaction between a trachoma strain of Chlamydia trachomatis and mouse fibroblasts (McCoy cells) in the absence of centrifugation. Infection and Immunity 31, 584-591.

LUCERo, M. E. \& KUo, C.-C. (1985). Neutralization of Chlamydia trachomatis cell culture infection by serovar-specific monoclonal antibodies. Infection and Immunity 50, 595-597.

Newhall, W. J., Batteiger, B. \& Jones, R. B. (1982). Analysis of the human serological response to proteins of Chlamydia trachomatis. Infection and Immunity 38, 1181-1189.

Peeling, R., Mclean, I. W. \& Brunham, R. C. (1984). In vitro neutralization of Chlamydia trachomatis with monoclonal antibody to an epitope on the outer membrane protein. Infection and Immunity 46, 484-488.

RIDDERHOF, J. \& BARnes, R. C. (1988). Enzyme immunoassay for measuring attachment of Chlamydia trachomatis to HeLa cells. Anmual Meeting of the American Society for Microbiology, D-7, p. 72.

Soderlund, G. \& Kinlstrom, E. (1983). Attachment and internalization of a Chlamydia trachomatis lymphogranuloma venereum strain by McCoy cells: kinetics of infectivity and effect of lectins and carbohydrates. Infection and Immunity 42, 930-935. Su, H., Zhang, Y.-X., Barrera, O., Watkins, N. G. \& Caldwell, H. D. (1988). Differential effect of trypsin on infectivity of Chlamydia trachomatis: loss of infectivity requires cleavage of major outer membrane protein variable domains II and IV. Infection and Immunity 56, 2094-2100.

VRETOU, E., Bezboruah, R. L., BARNES, R. C. \& Bose, S. K. (1988a). Host modulation of chlamydial adherence. Proceedings of the First Meeting of the European Society for Chlamydia Research, p. 101. Bologna, Italy: Societa Editrice Esculapio.

Vretou, E., Goswami, P. C., Bezboruah, R. L. \& Bose, S. K. (1988b). Host-controlled chlamydial adherence to human and murine cells. Annual Meeting of the American Society of Biochemistry and Molecular Biology. Journal of Cell Biology 107, $145 \mathrm{a}$.

Wenman, W. M. \& Meuser, R. V. (1986). Chlamydia trachomatis elementary bodies possess proteins which bind to eucaryotic cell membranes. Journal of Bacteriology 165, 602-607.

Zhang, Y.-X., Stewart, S., Joseph, T., TaYlor, H. R. \& Caldwell, H. D. (1987). Protective monoclonal antibodies recognize epitopes located on the major outer membrane protein of Chlamydia trachomatis. Journal of Immunology 138, 575-581. 